\title{
Probabilistic characterization of shear strength using results of direct shear tests
}

\author{
S. M. MILLER and L. E. BORGMAN (1984). Géotechnique 34, No. 2, 273-276
}

\section{Dr M. D. Bolton, Cambridge University Engineering Department}

The Authors describe a method by which shear box data can be manipulated to generate a statistical description of shear strength as a function of normal stress, using functions of the form

$$
y=a x^{b}+c
$$

This generates a convex limit envelope with a 'cohesion' intercept which bears a superficial resemblance to published data. However, the function fails to take account of the known principles of soil and rock mechanics.

On rock discontinuities, the equivalent angle of shearing at high stresses is $\phi_{\mu}{ }^{\prime}$, the basic angle of shearing of the material, which may be taken to be sensibly constant. Under small confining stresses the tendency for dilation, due to the overriding of asperities on discontinuity surfaces, creates correspondingly larger (secant) angles of shearing (Hoek \& Bray, 1974). This can be represented approximately by an analysis of the sliding of intermeshed saw blades, from which it becomes clear that

$$
\phi^{\prime}=\phi_{\mu}^{\prime}+\psi
$$

$\psi$ being the angle of overriding relative to the slip surface. The shearing of soils is not dissimilar, except that the discussion must be based on the basic angle of shearing at constant volume $\phi_{\text {crit }}^{\prime}$ which may similarly be enhanced by dilatiun if the stresses are not so large that fracture of the overriding particles intervenes before sliding can take place.

It may therefore be surmized, from the $\mathrm{Au}-$ thors' Fig. 2, specimen 2, that the angle of friction $\phi_{\mu}^{\prime}$ for the quartz monzonite does not exceed $26^{\circ}$. Any value of $\phi^{\prime}$ in excess of $26^{\circ}$ could reasonably be taken to indicate dilatancy due to irregularities in the surface of the discontinuity. The data suggest therefore that specimen 3 possessed a much rougher discontinuity than specimen 2, and that an increase in stress on any specimen has the usual effect of reducing the angle of dilatancy. The engineer is left with the usual problem of defining operative strengths, given the scatter in the data. If he fears that large slippages may previously have taken place on some discontinuity which he has not sampled, he will have to take $\phi^{\prime}=\phi_{\mu}{ }^{\prime} \ngtr 26^{\circ}$ on the basis that such a slip surface will have been smoothed. If he fears that many discontinuities are everywhere at least as smooth as specimen 2 , he will have to use strengths no greater than those, with a similar outcome. Only if he believes that his four specimens are representative of a single unique slip surface, every part of which must slip if the whole is to slip, would he wish to entertain any form of averaging. In such a situation, the Authors' method is apparently stating that two of the four specimens tested have strengths far outside one standard deviation from the Authors' 'expected' line. This seems paradoxical.

Even if the Authors' proccdure is correct, in the particular situation in which averaging is thought to be proper, it must be asked whether it is useful. The objective was to permit an engineer to indulge in a probabilistic geotechnical analysis. In such an analysis, the principle of effective stress must be employed. The total normal stress $\sigma$ on the plane of the discontinuity must be reduced at every point by the expected water pressure $u$ at that point, to obtain a normal effective stress $\sigma^{\prime}$. The $x$ axes of the Authors' diagrams should then have been labelled $\sigma^{\prime}$ rather than $\sigma$.

If a probabilistic analysis is to be undertaken, some means and standard deviations for $u$ must be decided on. This is likely to prove impossible, not lcast because slippage of rock masses causes cracks to open up which transform the mass permeability and consequently the seepage regime. Water pressures are a function of the regional climate and topography, soil infiltration characteristics, matrix permeability, joint geometries and openings, the possible presence of gouge material in open fissures and on bedding planes etc. As with the strength parameters themselves, it is more sensible to base a judgement of the seepage regime on a physically reasonably idealization into which an appropriate degree of determinate pessimism has been injected. The largest uncertainties are of the nature of the system itself. Probabilistic approaches usually ignore this and concentrate on describing the uncertainty of parameters in a 
system which has been completely determined. For this, some arbitrary distribution function is seized on in the absence of sound evidence, and which frequently permits parameters to take wholly unimaginable values. In this Discusser's view, such approaches are entirely misleading.

\section{REFERENCE}

Hoek, E. \& Bray, J. (1974). Rock slope engineering, ch. 5 . London: Institution of Mining and Metallurgy.

\section{Authors' reply}

Most of the concerns and opinions expressed by Dr Bolton are probably typical of those held by practising engineers who take a wary view of probabilistic methods.

The non-linear strength model, $y=a x^{b}+c$, was considered appropriate for results of smallscale direct shear tests because of its general nature (flexibility) and because it has been repeatedly confirmed by laboratory tests of joints in various rock types conducted by the first $\Lambda$ uthor and acquaintances in engineering practice. The flexibility of this particular non-linear model is noteworthy because, if the shear strength data are truly linear, then the model will so indicate (parameter $b$ will be unity or nearly equal to unity, and parameter $c$ will correspond to 'cohesion'). Besides the unpublished information mentioned, published evidence for a non-linear model include Jaeger (1971) and a list of references cited by Barton (1973, p. 292), who also states that it is probable that if more investigators had been interested in low levels of normal stress, or alternatively in very large ranges of normal stress, there would by now be universal acceptance of a fundamentally non-linear shear strength envelope for non-planar rock joints'. Thereforc this non-linear shear strength model for geologic discontinuities was considered to have a sound experimental and engineering basis, and was not selected because of its convenience, nor because of its 'superficial resemblance to published data' as implied by the Discusser.

Other non-linear models can be applied to shear strength data. The purpose of the Technical Note was not to evaluate their merit or lack of merit but rather to illustrate how a statistical procedure can be used to deal with test results from several like specimens. The major point is that the regression curves of the individual specimens should be combined instead of the individual $(x, y)$ points, a concept first suggested to the Authors by Dr R. D. Call, a rock engineering consultant with Call \& Nicholas, Inc, Tucson, Arizona.

It has been known for some time that peak shear strength estimates obtained by testing of laboratory-sized specimens are often higher than those determined in the field by back analyses of failures (e.g. Atkins \& Pasha, 1973) and, consequently, that the residual strengths obtained by laboratory testing should be used in the design of a major structure such as an open pit mine slope or an abutment for a large dam (Hoek \& Lunde, 1974). In the context of laboratory direct shear testing of natural rock joints, the true residual strength is often not measured, but rather a 'pseudo-residual' strength. This occurs because it is very difficult to reach the true residual strength of a non-planar joint surface because dilation persists during surprisingly large displacements of a small specimen (Barton, 1982, p. 172).

Why test natural joint surfaces at all? It would be better to test smooth, sawn surfaces of the rock substance to obtain an estimate of the residual, or base, friction angle of the rock. This friction angle is often 'taken to be sensibly constant' as indicated by the Discusser, an assumption which ignores the natural variability in the rock. Results of laboratory direct shear tests of smooth, sawn, lapped rock surfaces observed by the first Author commonly indicate some variation in the residual friction angle, especially for crystalline intrusive rocks where the angle may vary up to $2^{\circ}$ or $3^{\circ}$ among like specimens. This observed variation also includes measurement uncertainties associated with the laboratory testing process and interpretation of uncertainties associated with reducing the data. However, the fact of variability remains and if the most natural, realistic estimate of shear strength is to be obtained by testing small specimens then natural joints should be used. The pseudoresidual shcar strengths obtained from such testing logically will be representative of joint roughness on the scale of the specimen size. The example regression curves of shear strength given in the Technical Note are based on such pseudo-residual strengths and are assumed to represent samples of a given larger discontinuity surface along which potential sliding can occur in the field. Two scales of roughness are then assumed and should be incorporated into the shear strength estimate for the surface of potential sliding: firstly, the roughness on the scale of the laboratory specimens (say $10-30 \mathrm{~cm}$ ) which is represented by the pseudo-residual strengths and, secondly, the larger scale roughness (or waviness) observed when mapping joints in outcrops. These two scales bear a strong correspondence to those of the 'second-order' and 'firstorder' irregularities respectively described by Patton (1966). Both scales of roughness should 
be considered when the potential sliding surface is below the near-surface zone of weathering (Patton \& Deere, 1970), and both are variables that can be probabilistically described.

The narrowness of the standard deviation band about the mean regression curve shown in Fig. 2 of the Technical Note is largely due to the sample weighting procedure used in combining the sample results. The weight of an individual specimen was arbitrarily assigned to be the inverse of the standard error obtained by the regression analysis for that individual specimen. This is a reasonable assignment in a statistical sense, because the assumption made is that greater confidence can be placed in the reliability of a regression curve that has a lower standard error. However, in an engineering sense, the Authors agree with the Discusser that the resulting variance is probably too small, and that perhaps a more appropriate weighting scheme should be employed. The regression procedure is general enough to accommodate any weighting scheme proposed by the engineer. For instance, if each of the specimens is assumed to have equal weight, then the weight matrix is equal to the identity matrix. If the engineer places greater confidence on the test results from specimens with smoother joints, then those results can be given a relatively larger weight in the weight matrix. It is important to remember that statistical methods are tools in the hands of the engineer and they should assist rather than control the engineering process.

The applied (effective) normal stress on a potential sliding surface is primarily a function of the geometry and the density of the potential failure mass (these provide the weight) and the water pressure acting on the surface. Assuming that the geometry can be fairly well defined or predicted (a requirement for two-dimensional slope stability analyses), then the density and the water pressure are the variables that need to be quantified and described to provide an estimate of the applied normal stress, which is also considered to be a variable. Of the two, the water pressure is by far the more difficult to characterize because of the complexity of the system, as noted by the Discusser. However, by combining field data and numerical modeling of the geohydrologic regime along with engineering judgement, reasonable predictions can be made of the minimum and maximum water pressure on the potential sliding surface and even of the general character of its probability distribution. No compctent engineer would capriciously select just any convenient, arbitrary distribution function (especially one that allows unrealistic parameter values) but rather would rely on field and/or experimental evidence, engineering experience and common sense. Spatial correlations and interdependences among parameters should also be incorporated if the model of the system is to be as realistic as possible.

Geologic and hydrologic systems are complex. Probabilistic approaches, when tempered with engineering experience and judgement, provide a means to help to describe and analyze such systems quantitatively without relying on what level an 'appropriate degree of determinate pessimism' is to be set. Today's geotechnical engineers are being asked by open pit mine planners to assess the probability of slope instability for use in economic optimization studies (Kim, Cassun \& Hall, 1977) and by government agencies to assess probabilistically the risks with regard to stability and safety of dams and other civil projects. Are we to declare that the analysis cannot be done because the system is too complex? If we do, then the work will be attempted by professionals in other fields (such as statisticians) who have little or no training and experience in geotechnical matters. Would not a far better situation arise if geotechnical engineers were to become familiar with probability concepts and then to mold input from liaising statisticians into an approach rooted in geotechnical knowledge and experience?

\section{REFERENCES}

Atkins, J. T. \& Pasha, M. A. (1973). Controlling open-pit slope failures at Shirley Basin. Min. Engng 25, No. 6, 38-42.

Barton, N. (1973). Review of a new shear-strength criterion for rock joints. Engng Geol. 7, 287-332.

Barton, N. (1982). Shear strength investigations for surface mining. In Stability in surface mining (ed. C. O. Browner), Vol. 3, ch. 7, pp. 171-192. New York: American Institute of Mechanical Engineers.

Hoek, E. \& Lunde, P. (1974). Surface workings in rock. Proc. 3rd Congr. ISRM, Denver 1A, 613654.

Jaeger, J. C. (1971). Friction of rocks and stability of rock slopes. Géotechnique 21, No. 2, 97-134.

Kim, Y. C., Cassun, W. C. \& Hall, T. E. (1977). Pit slope manual supplement 5-3: financial computer programs. CANMET Report 77-6. Canada Centre for Mineral and Energy Technology (formerly Mines Branch, Energy, Mines and Resources Canada).

Patton, F. D. (1966). Multiple modes of shear failure in rock and related materials. $\mathrm{PhD}$ thesis, University of Illinois.

Patton, F. D. \& Deere, D. U. (1970). Significant geologic factors in rock slope stability. Proc. Symp. Theoretical Background to the Planning of Open Pit Mines with Special Reference to Slope Stability, Johannesburg, pp. 143-151. 